medRxiv preprint doi: https://doi.org/10.1101/2020.05.20.20078915; this version posted May 26, 2020. The copyright holder for this preprint (which was not certified by peer review) is the author/funder, who has granted medRxiv a license to display the preprint in perpetuity.

It is made available under a CC-BY-NC-ND 4.0 International license .

\title{
Total and Stroke Related Imaging Utilization Patterns During the COVID-19 Pandemic
}

Long H. Tu MD¹, Richa Sharma MD², Ajay Malhotra MD', Joseph L. Schindler MD², Howard P. Forman MD $\mathrm{MBA}^{1}$

${ }^{1}$ Yale Department of Radiology and Biomedical imaging, Yale University School of Medicine, 330 Cedar St, TE 2-214, New Haven, CT 06520

${ }^{2}$ Yale Department of Neurology, Yale University School of Medicine, 15 York St S, New Haven, CT 06510

\section{Corresponding author:}

Long H. Tu MD ${ }^{1}$

Phone: 860-882-3291

Email: long.tu@yale.edu

Address: 330 Cedar St, TE 2-214, New Haven, CT 06520

Each of the above authors have substantially contributed to the conception or design of the work, the writing and/or revision of the manuscript, approved the final version of the manuscript, and are accountable for the manuscript's contents. L.T., R.S., A.J., J.S., and H.P. designed the study. L.T. and R.S. extracted the data and performed the analysis. L.T., A.M., and H.P. drafted the manuscript with input from all authors.

The authors declare that they had full access to all of the data in this study and the authors take complete responsibility for the integrity of the data and the accuracy of the data analysis.

The authors declare no conflict of interest.

\begin{abstract}
During the COVID-19 pandemic, radiology practices are reporting a decrease in imaging volumes. We review total imaging volume, CTA head and neck volume, critical results rate, and stroke intervention rates before and during the COVID-19 pandemic. Total imaging volume as well as CTA head and neck imaging fell approximately $60 \%$ since the beginning of the pandemic. Critical results fell $60-70 \%$ for total imaging as well as for CTA head and neck. Compared to the same time frame a year prior, the number of stroke codes at the early impact of the pandemic had decreased approximately $50 \%$. Proportional reductions in total imaging volume, stroke-related imaging, and associated critical result reports during the COVID-19 pandemic raise concern for missed stroke diagnoses in our population.
\end{abstract}


medRxiv preprint doi: https://doi.org/10.1101/2020.05.20.20078915; this version posted May 26, 2020. The copyright holder for this preprint (which was not certified by peer review) is the author/funder, who has granted medRxiv a license to display the preprint in perpetuity. It is made available under a CC-BY-NC-ND 4.0 International license .

\section{Introduction}

In the midst of the COVID-19 pandemic, medical providers are seeing a decrease in patients seeking care for emergency conditions such as heart attacks and strokes. This was first reported on social and news media [1, 2]. Early hospital-level evidence also supports this observation [3, 4].

Radiology practices are reporting a concurrent decrease in imaging volumes of $50-70 \%[5,6]$. It is unclear to what extent factors such as patient self-selection, avoidance of necessary care, or changes in utilization contribute to this decrease. The incidence of some emergent medical conditions, such as stroke, is not expected to be directly impacted by infection prevention measures.

We obtained clinical and imaging data at a large, tertiary academic medical center during the COVID-19 pandemic and compared it with stroke data from the corresponding time period from 2019 to gain insight into the contributions of these various factors to imaging volume and critical result rate.

\section{Materials and Methods}

This study was approved for retrospective review by the institutional IRB and patient consent was waived. Review of imaging was performed from 1/1/2020 - 4/13/2020, spanning before and after the impact of COVID-19. Total imaging volume per day during this period was extracted and queried for critical results using key terms in institutional policy. Specific query for computed tomographic angiography (CTA) imaging of the head and head and related critical results was also obtained during the same time period. Chart review of patients with critical results on CTA head and neck was performed to ascertain the detected acute pathology. For each of the above, 7-day rolling averages were calculated.

\section{Results}

Total imaging volume decreased approximately $60 \%$ in the study period time frame. At the end of the study period, the 7-day average of studies per day was 916 (on 4/13/2020), compared to 2462 (on $1 / 13 / 2020)$. A sharp change was seen concurrent with response measures for COVID-19 starting in midMarch, beginning on 3/16/2020. Total critical result rates also decreased to an approximately proportionally degree, $60-70 \%$ (Figure 1). At the end of the study period, the 7-day average of critical results per day was 70 (on 4/13/2020), compared to 209 (on 1/13/2020). CTAs performed also declined approximately $60 \%$ in volume during this time frame. At the end of the study period, the 7-day average was 3.3 (on 4/13/2020), compared to 10.7 (on 1/13/2020). The exact magnitude of decrease is difficult to describe given variability in CTAs performed on a day-to-day and week-to-week basis. The rate of critical results and ischemic pathologies found on imaging is below usual trends, with similar decreases in magnitude (Figure 2). The exact decrease in these figures is similarly difficult to quantify. The imaging volumes have remained at the lower numbers since the mid-March decrease. The number of stroke codes showed a roughly $50 \%$ decrease in the initial week of the pandemic compared to the corresponding period in 2019, with even greater decrease in number of patients getting intravenous thrombolysis (IVT) and endovascular thrombectomy (EVT). However, the number of stroke codes and IVT administrations in the subsequent three weeks have increased but remain low compared to the 2019 numbers. The number of EVTs has begun to increase from this low point. 
medRxiv preprint doi: https://doi.org/10.1101/2020.05.20.20078915; this version posted May 26, 2020. The copyright holder for this preprint (which was not certified by peer review) is the author/funder, who has granted medRxiv a license to display the preprint in perpetuity.

It is made available under a CC-BY-NC-ND 4.0 International license .

\section{Discussion}

Our data demonstrate an approximate decrease of $60 \%$ total imaging volume during the COVID-19 pandemic. Total critical result numbers have also decreased by $60-70 \%$. A large proportion of this change may reflect postponement of outpatient imaging studies and exams of ultimately non-emergent pathologies. The proportional decrease in critical results however suggests that acute pathologies in our population may not be presenting to medical attention. There is a similar trend when looking at only CTA head and neck exams with regard to total volume, critical results, and ischemic pathologies. There was an initial dramatic decrease in the stroke codes in the first week of the crisis, with increased numbers since, although still lower compared to 2019 volumes.

Reductions in imaging volume, stroke related findings, and stroke codes during the COVID-19 pandemic raise concern for missed stroke diagnoses, a worrisome possibility. Further work is necessary to assess the long-term impact of this trend.

\section{References}

1. Krumholz, HM. Where Have All the Heart Attacks Gone? The New York Times. Doctors. 2020 Mar.

2. Sheth, K. Hospital admissions for strokes appear to have plummeted, a doctor says, a possible sign people are afraid to seek critical help. The Washington Post. Health \& Science. Perspective. 2020 Apr.

3. Garcia S, Albaghdadi MS, Meraj PM, Schmidt C, Garberich R, Jaffer FA, Dixon S, Rade JJ, Tannenbaum M, Chambers J, Huang PP. Reduction in ST-Segment Elevation Cardiac Catheterization Laboratory Activations in the United States during COVID-19 Pandemic. Journal of the American College of Cardiology. 2020 Apr 10.

4. Baracchini C, Pieroni A, Viaro F, Cianci V, Cattelan AM, Tiberio I, Munari M, Causin F. Acute stroke management pathway during Coronavirus-19 pandemic. Neurological Sciences. 2020 Apr 9:1.

5. Cavallo JJ, Forman HP. The Economic Impact of the COVID-19 Pandemic on Radiology Practices. Radiology. 2020 Apr 15:201495.

6. Walach E. COVID-19 Impact on CT Imaging Volume. Aidoc Blog; https://www.aidoc.com/blog/ctimaging-volumes-

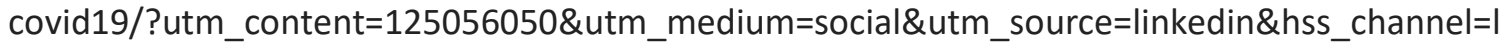
is-xca2lgYf3G; Updated Apr 16, 2020. Accessed Apr 20, 2020. 


\section{Figure 1:}

Daily total imaging volume at our institution decreased approximately $60 \%$, from a range of $2400-2500$ studies per day to 900-100 studies per day after the impact of COVID-19. Critical results in imaging reports decreased $60-70 \%$, from a range of 200-220 per day to $70-75$ per day. The sharp decrease between $3 / 16 / 2020$ and $3 / 23 / 2020$ coincides with major institutional response measures and implementation of social distancing guidelines by the CDC.

\section{Figure 2:}

Total CTA head and neck imaging at our institution decreased from a range of 8-15 studies per day to 06 studies per day. Critical results and ischemic pathologies are seen at a decreased rate compared to before the week of 3/16/2020 - 3/23/2020. Critical results in late March and early April range from 0-0.5 per day for 7-day rolling averages. Pre-COVID, this was 1-2 critical results per day. Comparison of ischemic pathologies before and during COVID-19 is difficult due to the low numbers, though follows a similar trend as overall critical results, reaching minimums not otherwise seen in 2020. 
Daily Total Imaging Exams and Critical Results

(7-Day Rolling Averages for 1/13/2020 - 4/13/2020)

3000

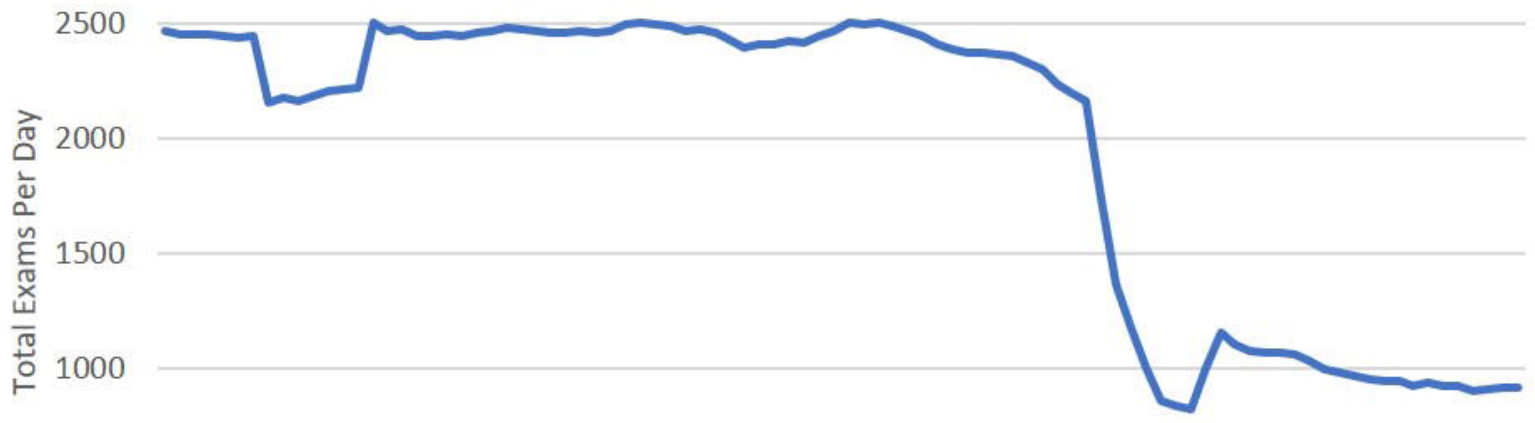

500

0

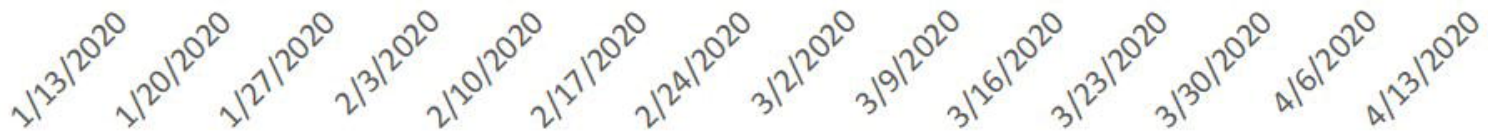

Date (MM/DD/YYYY)

-Total Imaging Exams $\quad$ Critical Results 
Daily CTA Head and Neck Exams, Critical Results, and Ischemic Stroke Findings

(7-Day Rolling Averages for 1/13/2020 - 4/13/2020)

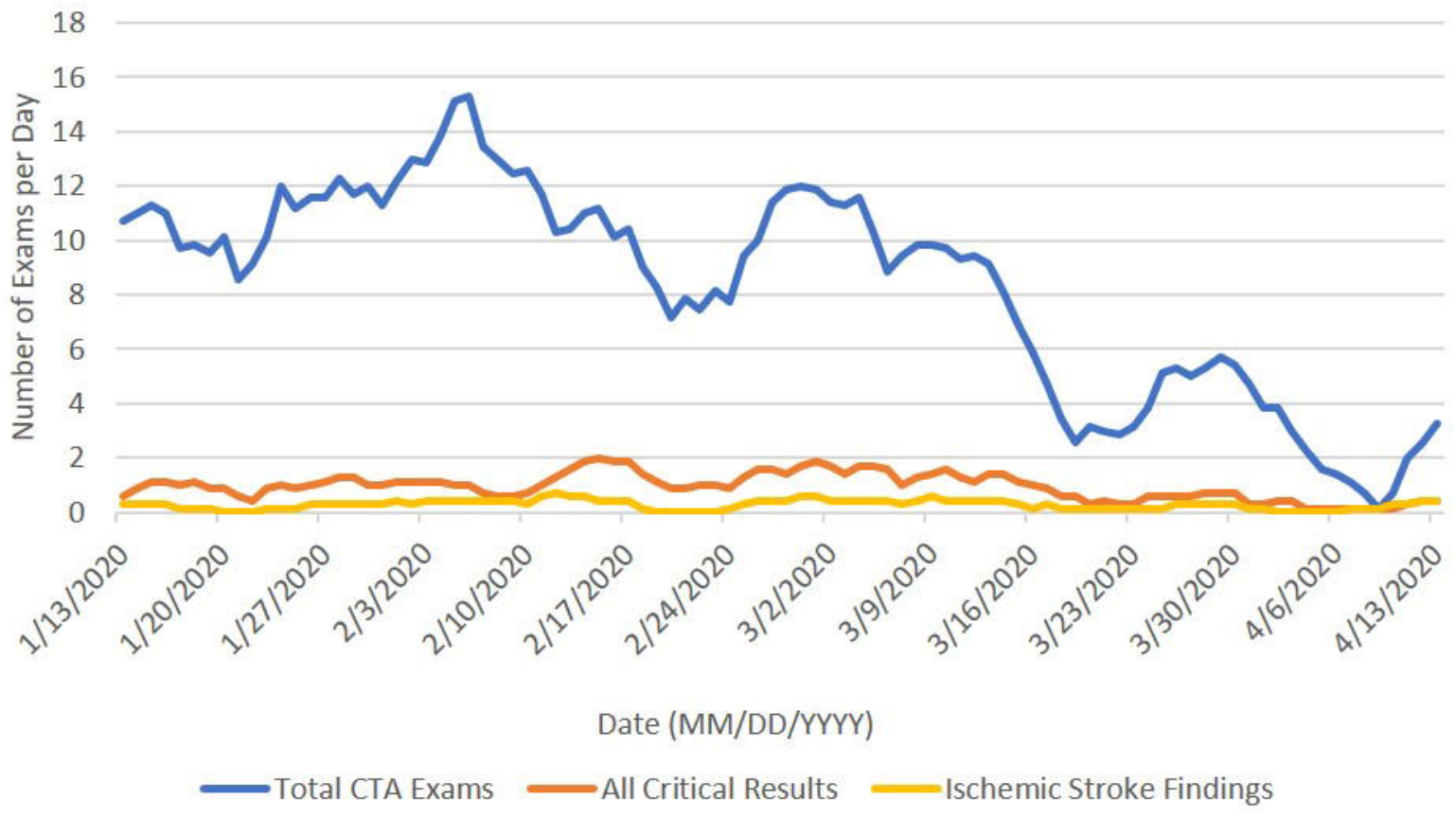

